\title{
Frequency tuning varactor-loaded reconfigurable antenna for m-WiMAX and WLAN applications
}

\author{
S. M. Shah', K. Hamdan', Z. Z. Abidin" F. C. Seman ${ }^{4}$, S. A. Hamzah ${ }^{5}$, N. Katiran' ${ }^{6}$, F. Zubir ${ }^{7}$ \\ 1,2,3,4,5,6 Research Centre for Applied Electromagnetics, Universiti Tun Hussein Onn Malaysia, Johor, Malaysia. \\ ${ }^{7}$ School of Electrical Engineering, Universiti Teknologi Malaysia, Johor, Malaysia.
}

\begin{tabular}{l} 
Article Info \\
\hline Article history: \\
Received Oct 11, 2018 \\
Revised Dec 12, 2018 \\
Accepted Dec 26, 2018 \\
\hline Keywords: \\
Microstrip antenna \\
m-WiMAX \\
Reconfigurable antenna \\
Varactor diode \\
WLAN
\end{tabular}

\begin{abstract}
A design approach for a microstrip patch antenna to achieve the reconfigurable dual-band operation with a tunable device is presented in this work. The approach uses a BB833 varactor diode in the middle of a slotted patch antenna which which is able to produce dual-band resonant frequencies. The reconfigurable antenna is designed and simulated in CST Microwave Studio ${ }^{\circledR}$ software and is later, fabricated on a FR-4 substrate with a dielectric constant, $\varepsilon_{\mathrm{r}}$ of 4.5 , loss tangent, $\tan \delta$ of 0.019 and thickness, h of $1.6 \mathrm{~mm}$. By changing the DC voltages of the varactor diode, different capacitance values of the varactor diode are obtained which dictate the specific resonant frequencies. From the simulation results, the capacitance value of $0.5 \mathrm{pF}$ with a bias voltage of $2.0 \mathrm{~V}$ is chosen as it produces the required dual-band resonant frequencies at $3.38 \mathrm{GHz}$ and $5.37 \mathrm{GHz}$ for desired applications in the m-WiMAX and WLAN bands.
\end{abstract}

Copyright (C) 2019 Institute of Advanced Engineering and Science. All rights reserved.

\section{Corresponding Author:}

Shaharil Mohd Shah,

Research Centre for Applied Electromagnetics,

Universiti Tun Hussein Onn Malaysia,

86400 Batu Pahat, Johor, Malaysia.

Email: shaharil@uthm.edu.my

\section{INTRODUCTION}

Wireless communication has progressed very rapidly in recent years. The rapid development is bringing about a wave of new wireless devices and systems to meets the demands of multimedia applications. Multi-frequency and multi-mode devices such as cellular phones, Wireless Local Area Networks (WLANs) and Wireless Personal Area Networks (WPANs) place several demands on the antennas. Therefore, radio frequency (RF) engineers are facing continuous challenges to design antenna with small-volume but still operating in multiband frequencies. To solve these problems, reconfigurable antennas offer a good solution because they can expand the capability of the communication systems. In addition, the reconfigurable antennas are more desired in wireless communication applications because of their flexibility and their ability to satisfy the changing systems requirements. Reconfigurable antennas that have the ability to radiate at multiple frequencies are required in the modern communication systems. By reconfiguring its operating frequencies, the reconfigurable antenna is able to accommodate the numerous frequency bands of wireless communication systems [1]. Various techniques have been adopted to achieve the reconfiguration ability in antennas such as the used of switching and tuning devices on the antennas. Field Effects Transistor (FET) and Positive-Intrinsic-Negative (PIN) diodes are the examples of active switches and varactor diode acts as a tuning device [2]. Apart from that, by using photoconductive switching elements which are based on optically tuning concept can also reconfigure an antenna [3].

Planar antennas, such as microstrip and printed antenna, have the attractive features of low profile, small size, and conformability to mounting host and very promising candidates for satisfying the design consideration. Microstrip antennas have become popular in the 1970s primarily for space borne applications. 
Today the antennas are used for government and commercial applications. Microstrip antennas consist of a metallic patch on the grounded substrate. The metallic patch can take many configurations. However, because of the ease of analysis, fabrication and attractive radiation characteristics, rectangular and circular patches are the most popular [4]. These antennas can be mounted on the surface of high performance aircraft, spacecraft, satellites, missiles, cars and even handheld mobile telephones [5].

This work is focusing on the design, simulation and fabrication of a reconfigurable antenna that uses a BB833 varactor diode from Infineon Technologies to tune the frequencies to operate in the wirereless frequency bands. Varactor diode is a solid-state semiconductor device that is used to tune the frequency range of the antenna [6]. By changing the bias voltages on the diode, it will vary the capacitances and tune the resonant frequencies. The design and simulation processes are done by using CST Microwave Studio® (MWS) software. The simulation result is optimized to achieve the best performance of the antenna. Then, the antenna is fabricated on a FR-4 substrate with a relative dielectric constant, $\varepsilon_{\mathrm{r}}$ of 4.5 , thickness, h of 1.6 $\mathrm{mm}$ and loss tangent, $\tan \delta$ of 0.019 . The measurements of the antenna is performed by using the ZVB14 Rohde \& Schwarz Vector Network Analyser (VNA). Based on the simulation results, the capacitance of 0.5 $\mathrm{pF}$ with a bias voltage of $2.0 \mathrm{~V}$ is chosen as it produces the desired dual-band resonant frequencies. As a result, the varactor diode has successfully tuned the resonant frequencies of the antenna to operate in the $\mathrm{m}$ WiMAX and WLAN bands at $3.50 \mathrm{GHz}$ and $5.20 \mathrm{GHz}$.

\section{RESEARCH METHODOLOGY}

In order to produce a working reconfigurable antenna with a varactor diode, a few antennas have been designed and simulated in an orderly manner. This stage is conducted to investigate the direction and movement of the resonant frequencies for each antenna and how the placement of the varactor diode in the structure of the antenna can tune the resonant frequencies to operate in the desired frequency bands. In this work, the antenna is optimized to work in the m-WiMAX and WLAN application bands.

\subsection{Microstrip Patch Antenna}

The first design of the antenna is a microstrip patch antenna that operates at $3.50 \mathrm{GHz}$. The dimensions of the antenna have been calculated from the formulas in [7]. Figure 1 shows the microstrip patch antenna at $3.50 \mathrm{GHz}$ and Table 1 lists the dimensions of the antenna. The dimensions of the microstrip patch antenna are similar for all antennas in this work.

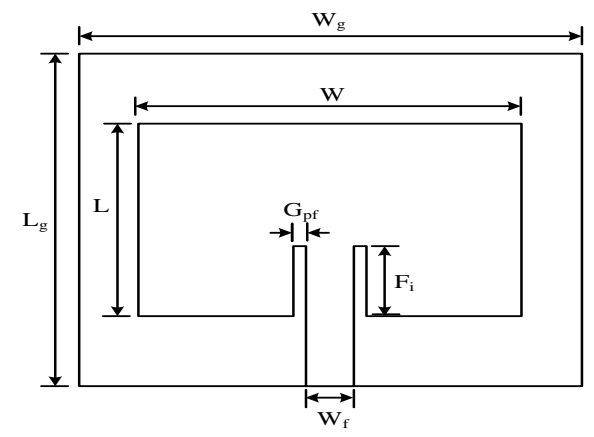

Figure 1. Microstrip antenna at $3.50 \mathrm{GHz}$

Table 1. Dimensions of the Microstrip Patch Antenna at $3.50 \mathrm{GHz}$

\begin{tabular}{cccc}
\hline Parameter & Value $(\mathrm{mm})$ & Parameter & Value $(\mathrm{mm})$ \\
\hline$L_{g}$ & 33 & $W_{f}$ & 3.04 \\
$W_{g}$ & 35.9 & $G_{p f}$ & 0.14 \\
$L$ & 19.9 & $F_{i}$ & 7.5 \\
$W$ & 25.9 & & \\
\hline
\end{tabular}

\subsection{Microstrip Patch Antenna with a Slot and Microstrip Slot Antenna with an Ideal Switch}

Next, a $12 \times 1 \mathrm{~mm} 2$ slot is introduced in the middle of the patch in the second design of the antenna. A parametric study is performed to obtain the best location of the slot with respect to the upper edge of the patch. From the parametric study, the best location of the slot is at $4 \mathrm{~mm}$ from the upper edge of the patch for 
m-WiMAX and WLAN applications. In the third design, an ideal switch is introduced in the middle of the slot to observe the changes in resonant frequency and reflection coefficient. A parametric study is also conducted to determine the best location of the ideal switch. The ideal switch is a copper bridge with a dimension of $1 \times 1 \mathrm{~mm} 2$. Figure 2 shows the microstrip patch antenna with a slot and the microstrip slot antenna with an ideal switch (copper bridge).

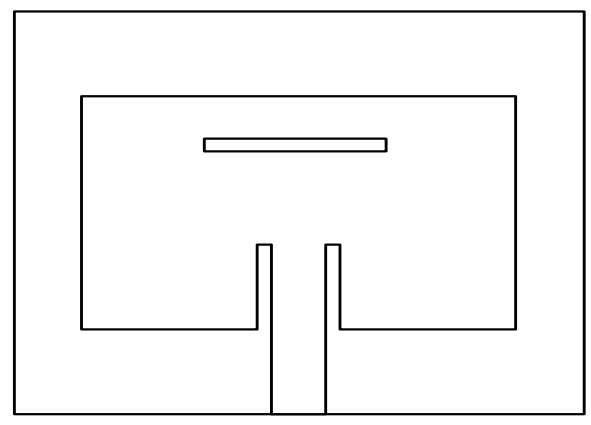

(a)

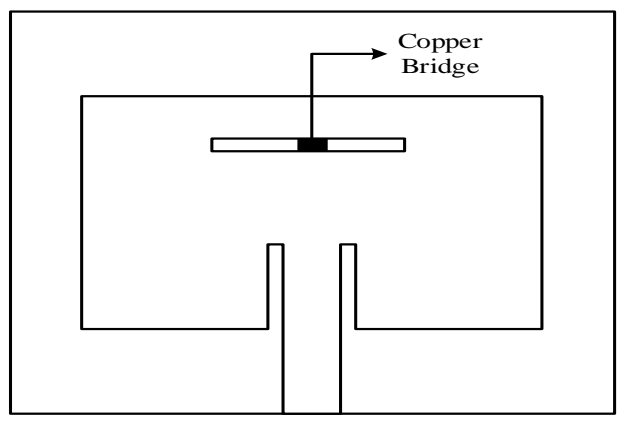

(b)

Figure 2. Microstrip patch antenna: (a) With a slot; (b) With a copper bridge (ideal switch) across the slot

\subsection{Reconfigurable Antenna with a BB833 Varactor Diode}

The copper bridge is replaced by a varactor diode in the fourth design of the antenna. Initially, a SMV1405 varactor diode is chosen. However, the production has been discontinued by Skyworks Solutions, Inc. Therefore, it is replaced with a BB833 varactor diode from Infineon Technologies. The varactor diode is represented by a discrete port in CST MWS $®$ software which can be viewed in Figure 3(a). The actual varactor diode model is represented by the *.s $2 p$ file that is supplied by the manufacturer. The *.s2p is the 2port $\mathrm{S}$-parameters file which is unique for each capacitance and bias voltage of the varactor diode. However, due to the unavailability of the BB833 varactor diode *.s2p files from the manufacturer, the *.s2p files of SMV1405 varactor diode from Skyworks Solutions, Inc. are used instead. In the schematic diagram of the CST MWS ${ }^{\circledR}$ software, the *.s2p file is transferred to the Touchstone file. Figure 3(b) shows the schematic diagram of the reconfigurable antenna with the $* . s 2 p$ file of the varactor diode.

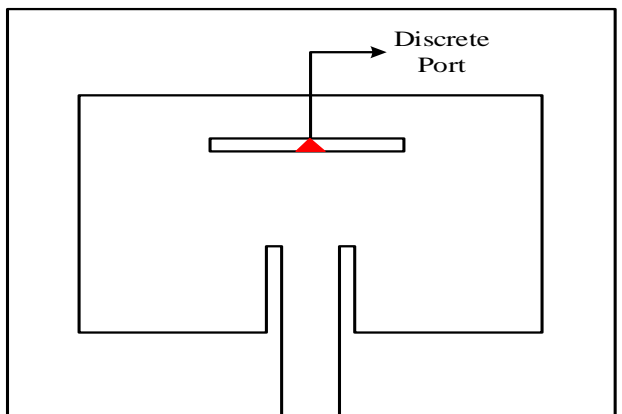

(a)

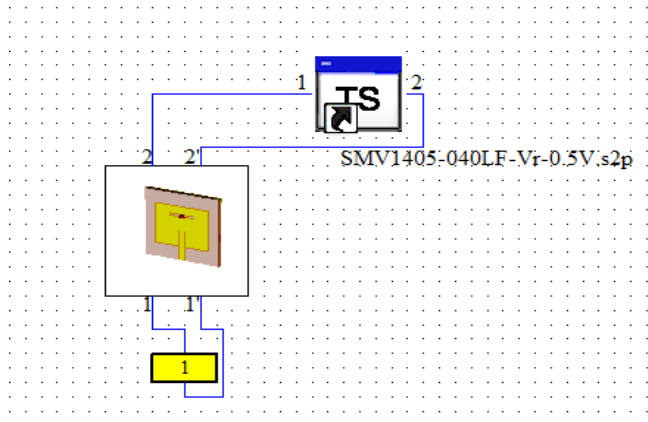

(b)

Figure 3. The reconfigurable antenna with a BB833 varactor diode: (a) The discrete port to represent the varactor diode; (b) The *.s2p file to represent the varactor diode in the schematic diagram of CST MWS® software

\subsection{Antenna Fabrication}

The antennas are fabricated on the FR-4 substrate with a relative dielectric constant, $\varepsilon_{\mathrm{r}}$ of 4.5 , thickness, $\mathrm{h}$ of $1.6 \mathrm{~mm}$ and loss tangent, $\tan \delta$ of 0.019 . The measurements are conducted by using the ZVB14 Rohde \& Schwarz Vector Network Analyzer (VNA). Figure 4 shows the fabricated antennas in this work. 


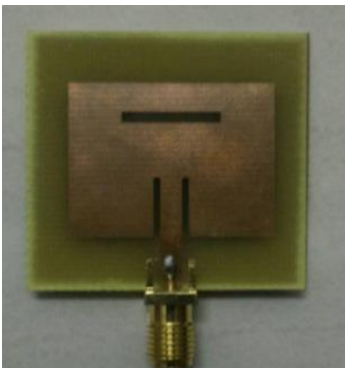

(a)

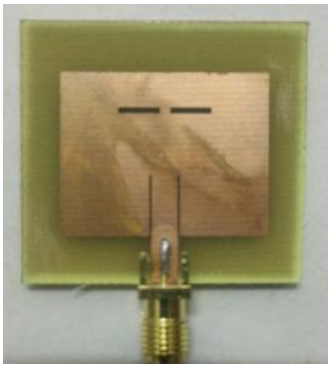

(b)

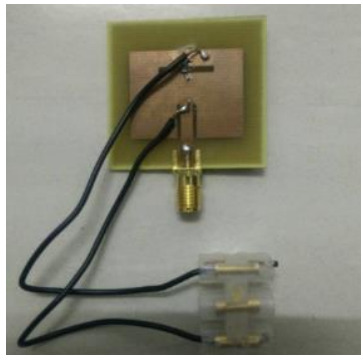

(c)

Figure 4. The fabricated antennas: (a) Microstrip patch antenna with a slot; (b) Microstrip patch antenna with a copper bridge (ideal switch); (c) Reconfigurable antenna with a BB833 varactor diode

\section{RESULTS AND ANALYSIS}

Due the lack of facilities, only the reflection coefficient of the antennas is measured in this work. Furthermore, the measurements of the reconfigurable antenna with a varactor diode are not allowed to be performed to avoid any damages to the RF port of the ZVB14 Rohde \& Schwarz VNA. Therefore, only the simulation results of the reconfigurable antenna with a varactor diode is shown in this work.

\subsection{Microstrip Patch Antenna and Microstrip Patch Antenna with a Slot}

Figure 5 shows the simulated reflection coefficient of the microstrip patch antenna. Since the antenna is not fabricated and measured, only the simulation result is shown. The reflection coefficient of the antenna is -20.87 at $3.50 \mathrm{GHz}$.

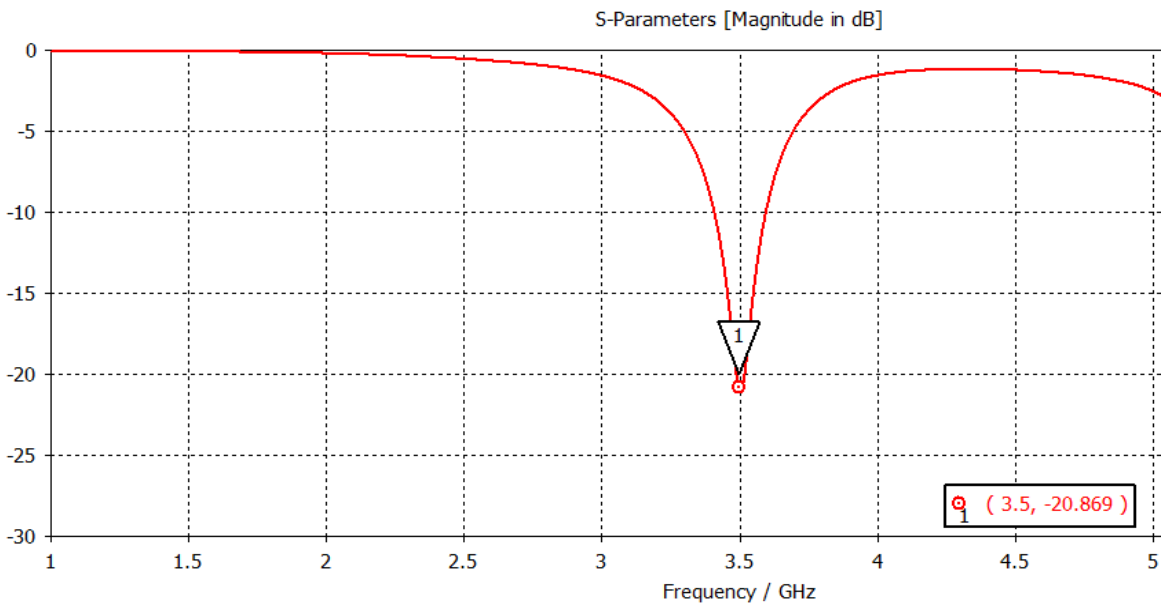

Figure 5. Simulated reflection coefficient of the microstrip patch antenna at $3.50 \mathrm{GHz}$

Figure 6 shows the comparison of the simulated and measured reflection coefficients of the microstrip patch antenna with a slot. From the figure, the previously simulated resonant frequency at 3.50 $\mathrm{GHz}$ refer Figure 4 has been shifted to $3.315 \mathrm{GHz}$ due to presence of the slot. At the same time, another resonant frequency is generated at $5.34 \mathrm{GHz}$. The reflection coefficients at those resonant frequencies are $15.94 \mathrm{~dB}$ and $-22.11 \mathrm{~dB}$. Therefore, it is shown that the presence of a slot in the structure of the antenna produces dual-band resonant frequencies. There is a good agreement between the simulation and measurement results.

The display of the measured reflection coefficient on the VNA can be viewed in Figure 7. From the figure, the antenna resonates at $3.37 \mathrm{GHz}$ and $5.55 \mathrm{GHz}$ which vary slightly from the simulated result. This might be attributed to the fabrication inconsistencies. The reflection coefficients are $-19.12 \mathrm{~dB}$ at $3.37 \mathrm{GHz}$ and $-17.92 \mathrm{~dB}$ at $5.55 \mathrm{GHz}$ which are reasonable. 


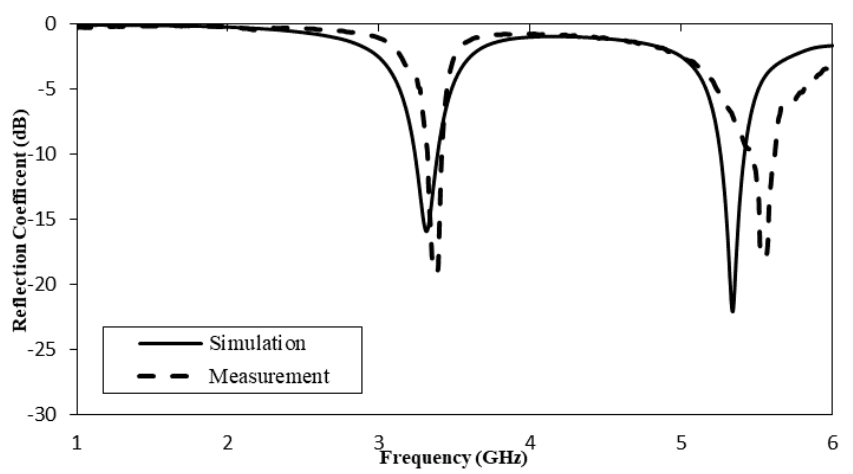

Figure 6. Reflection coefficients of the microstrip patch antenna with a slot

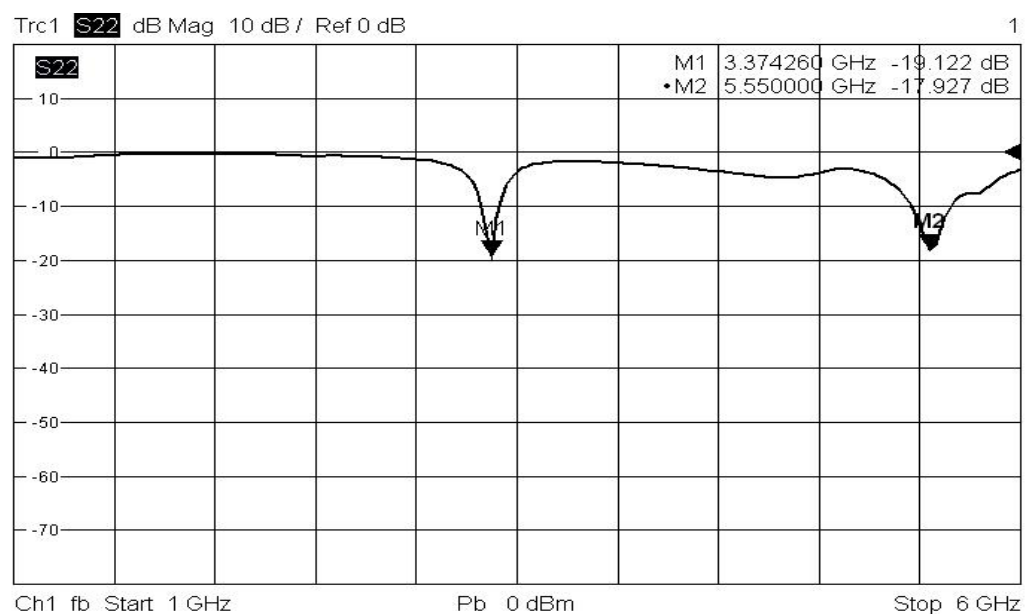

Figure 7. Measured reflection coefficient of the microstrip patch antenna with a slot

\subsection{Microstrip Slot Antenna with an Ideal Switch}

Figure 8 shows the comparison of the simulated and measured reflection coefficients of the antenna with an ideal switch. From the figure, the previously simulated resonant frequencies at $3.315 \mathrm{GHz}$ and 5.34 $\mathrm{GHz}$ refer Figure 5 have been shifted slightly to $3.4 \mathrm{GHz}$ and $5.3 \mathrm{GHz}$ due to the presence of the copper bridge as an ideal switch. The copper bridge has resulted in the current travels shorter since it passes through the copper bridge instead of going round the slot [8]. Therefore, the resonant frequency increases which explains the shift in the first resonant frequency of the antenna. The reflection coefficient at $3.40 \mathrm{GHz}$ is -11 $\mathrm{dB}$ and at $5.30 \mathrm{GHz}$ is $-16.16 \mathrm{~dB}$. Figure 9 shows the measured reflection coefficient of the antenna. The reflection coefficients are $-26.88 \mathrm{~dB}$ at $3.426 \mathrm{GHz}$ and $-12.30 \mathrm{~dB}$ at $5.51 \mathrm{GHz}$.

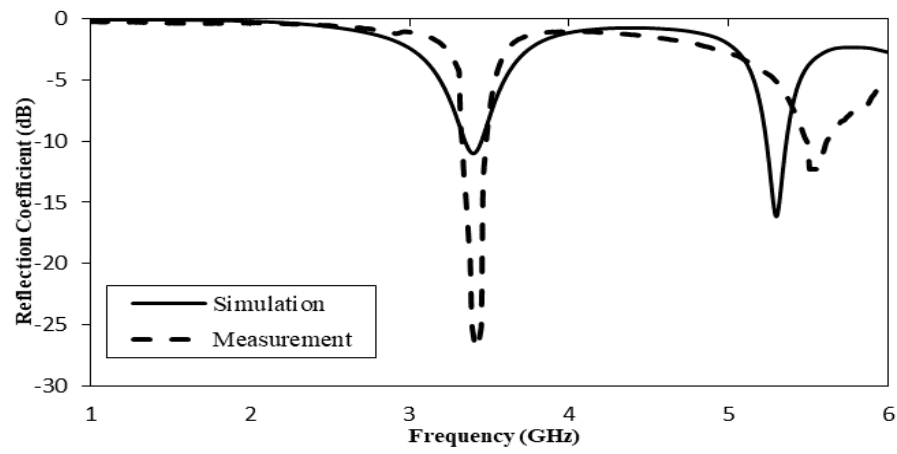

Figure 8. Reflection coefficient of the microstrip slot antenna with an ideal switch (copper bridge) 


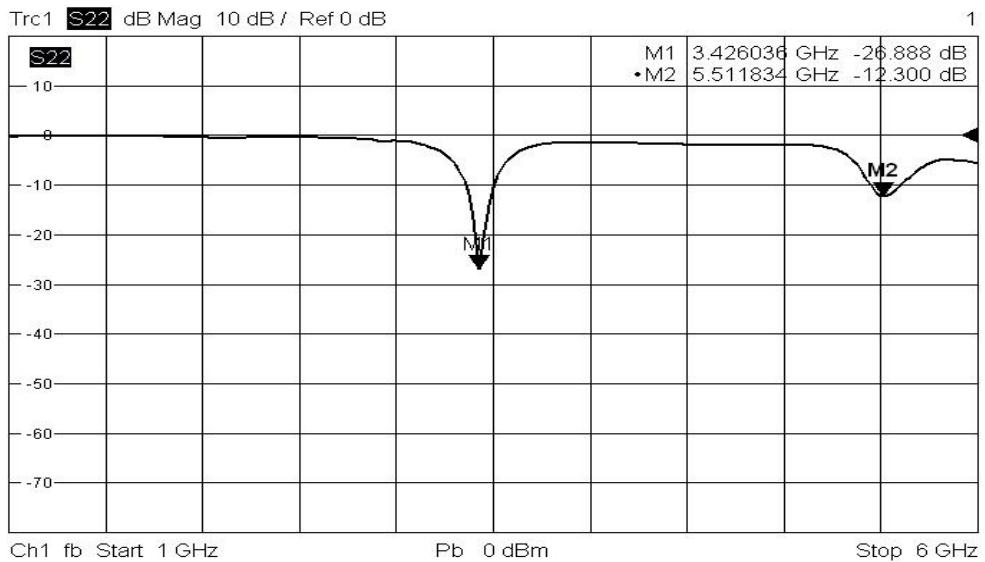

Figure 9. Measured reflection coefficient of the microstrip slot with an ideal switch (copper bridge)

\subsection{Reconfigurable Antenna with a BB833 Varactor Diode}

Different capacitance values of the varactor diode can be varied by changing the DC voltages which dictate the presence of specific resonant frequencies. The capacitance value and DC voltage of each varactor diode is unique for each *.s $2 p$ file. From the simulation results, the varactor diode with the capacitance value of $0.5 \mathrm{pF}$ with a bias voltage of $2.0 \mathrm{~V}$ produces the desired resonant frequencies for m-WiMAX and WLAN applications. Figure 10 shows the simulated reflection coefficients of the antenna. From the figure, the resonant frequencies at $3.40 \mathrm{GHz}$ and $5.30 \mathrm{GHz}$ refer Figure 8 have been slightly shifted to $3.38 \mathrm{GHz}$ and $5.375 \mathrm{GHz}$ due to presence of the varactor diode. The reflection coefficients at those particular frequencies are $-21.86 \mathrm{~dB}$ and $-21.17 \mathrm{~dB}$ which show a reasonable improvement as compared to the antenna with an ideal switch.

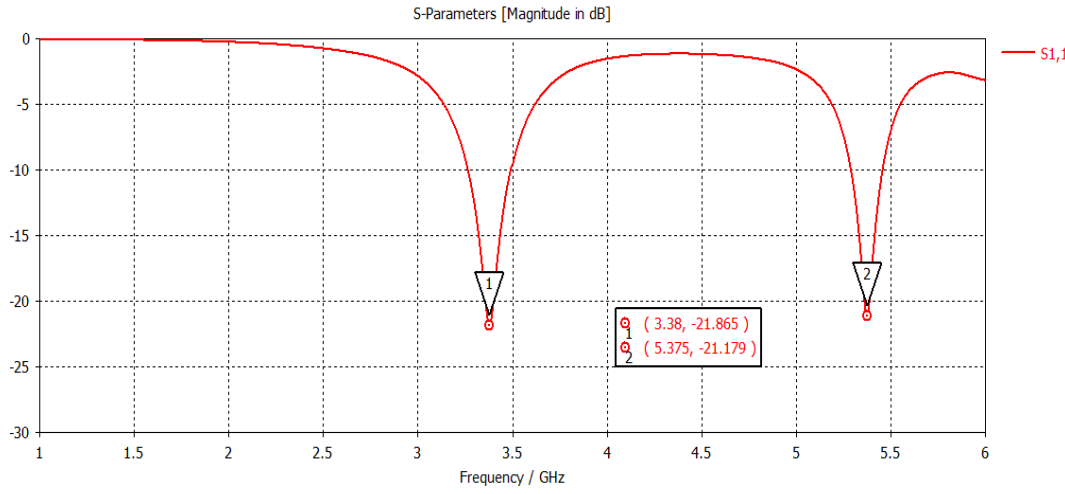

Figure 10. Simulated reflection coefficient of the reconfigurable antenna with a varactor diode

\section{CONCLUSION}

A reconfigurable antenna with a BB833 varactor diode is designed, simulated and fabricated in this work. The reconfigurable antenna is tuned by the varactor diode to operate at $3.38 \mathrm{GHz}$ and $5.37 \mathrm{GHz}$ frequency bands for m-WiMAX and WLAN applications. The capacitance values of the varactor diode are varied by varying the bias voltages. It is found that the varactor diode with the capacitance value of $0.5 \mathrm{pF}$ and a bias voltage of $2.0 \mathrm{~V}$ is the most preferred since it generates the desired dual-band resonant frequencies required in this work. Due to the unavailable device in the laboratory, the measurement of the reconfigurable antenna with a varactor diode could not be performed to avoid any damages to the RF port of the ZVB14 Rohde \& Schwarz VNA. Therefore, only the simulation results of the reconfigurable antenna with a varactor diode is shown in this work. However, two antennas are fabricated and measured namely, microstrip patch antenna with a slot and microstrip slot antenna with an ideal switch (copper bridge) but due to the lack of facilities, only the reflection coefficients are measured. From the simulation and measurement results, it is observed that they agree well with each other. 


\section{ACKNOWLEDGEMENTS}

The author would like to acknowledge Universiti Tun Hussein Onn Malaysia for the funding of this work under the Internal Grant of Tier 1 (H247).

\section{REFERENCES}

[1] Rouissi, Ines, Jean Marie Floc'h, Hatem Rmili, and Hichem Trabelsi. "Design of a frequency reconfigurable patch antenna using capacitive loading and varactor diode." In Antennas and Propagation (EuCAP), 2015 9th European Conference on, pp. 1-4. IEEE, 2015.

[2] Haupt, Randy L., and Michael Lanagan. "Reconfigurable antennas." IEEE Antennas and Propagation Magazine 55, no. 1 (2013): 49-61.

[3] Dixit, L., and P. K. S. Pourush. "Radiation characteristics of switchable ferrite microstrip array antenna." IEE Proceedings-Microwaves, Antennas and Propagation 147, no. 2 (2000): 151-155.

[4] Balanis, Constantine A. "Antenna Theory: Analysis \& Design, John Willey \& Sons." Inc. Publication (1997).

[5] Wong, Kin-Lu. "Advanced Planar Antenna Designs for Wireless Devices [Z]." Taiwan: Dept. of Electrical Engineering National Sun Yat-Sen University Kaohsiung 80424.

[6] Frenzel, Louis. Principles of electronic communication systems. McGraw-Hill, Inc., 2007.

[7] Chitra, R. Jothi, K. Jayanthi, and V. Nagarajan. "Design of microstrip slot antenna for WiMAX application." In Automation, Computing, Communication, Control and Compressed Sensing (iMac4s), 2013 International MultiConference on, pp. 645-649. IEEE, 2013.

[8] Yang, Fan, and Yahya Rahmat-Samii. "Patch antennas with switchable slots (PASS) in wireless communications: Concepts, designs, and applications." IEEE Antennas and propagation Magazine 47, no. 2 (2005): 13-29.

\section{BIOGRAPHIES OF AUTHORS}

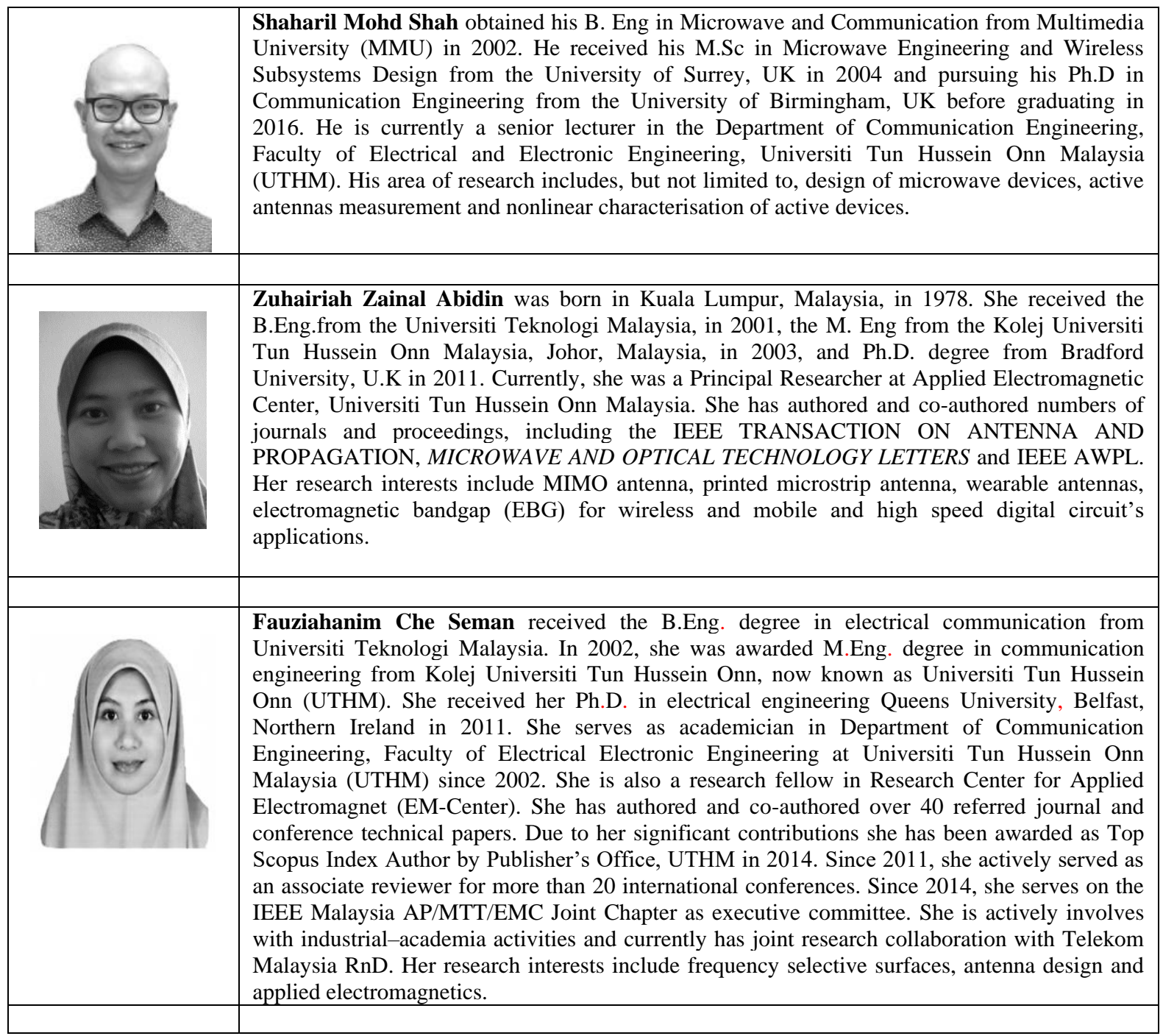




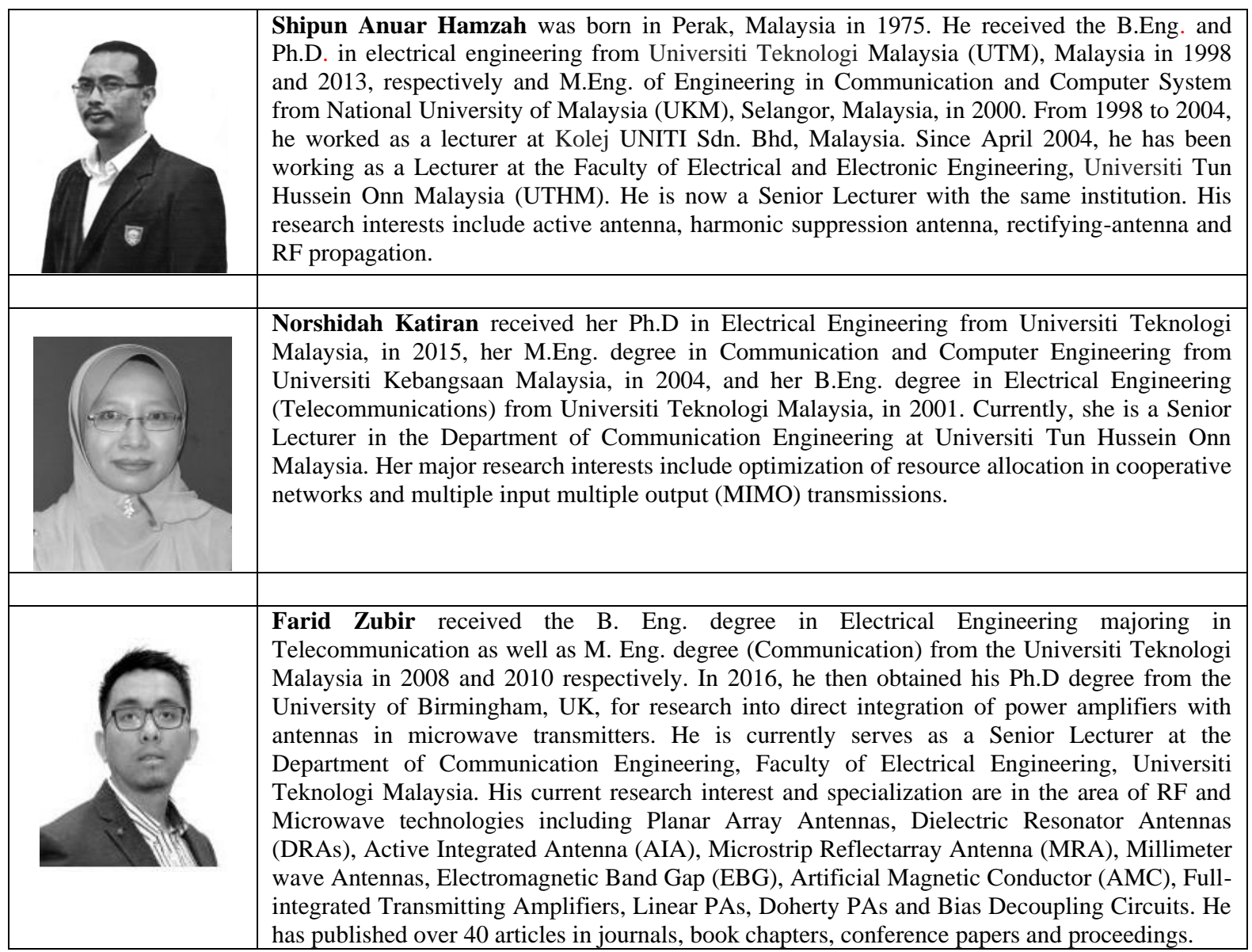

